\title{
Foreign body in the myocardium as a cause of constrictive pericarditis
}

\author{
Y. K I S H O N, Y. P A U Z N E R, F. D A L I T H, A N D \\ HENRY N. NEUFELD \\ From the Heart Institute, Department of Cardiothoracic Surgery and Department of Radiology, \\ Tel-Hashomer Government Hospital, the University of Tel-Aviv Medical School, Israel
}

An unusual case of constrictive pericarditis, caused by lodging of a needle in the heart wall, is presented and discussed. Attention is focused on the rapid development of the constriction and the benefit gained from surgical intervention.

Constrictive pericarditis due to foreign bodies is exceedingly rare. During the past three decades the relationship between trauma and constrictive pericarditis has been established in welldocumented cases (Warburg, 1933 ; Glenn, 1940 ; Straus, 1944 ; Watts and Toone, 1945 ; Mortensen and Warburg, 1948 ; McKusick, 1952).

The injurious agents are many, including needles (Straus, 1944) and knives (McKusick, 1952). The relationship between trauma and the development of constrictive pericarditis has been questioned by Robertson and Arnold (1962), and McKusick (1952) states that trauma should not be overlooked in the aetiology, although in his view this cause has never been proven unequivocally.

It is the purpose of this paper to describe another case of this condition. Of special interest is the fact that constrictive pericarditis developed very rapidly in this patient, a point which raises the question of the need for prompt surgical intervention in similar cases.

\section{CASE REPORT}

A 32-year-old woman was admitted to the TelHashomer Hospital in August 1953 because of congestive heart failure. One month earlier, while under treatment in a mental hospital, the patient attempted suicide by inserting needles into her chest. Within less than a week she developed fever and transient arrhythmias. She had several episodes of peripheral shock.

Physical examination in our hospital revealed an undernourished woman in no acute distress. Her body temperature was $38^{\circ} \mathrm{C}$., the blood pressure was $120 /$ $100 \mathrm{~mm} . \mathrm{Hg}$, and the heart was in sinus rhythm at a rate of 130 per minute. The cardiac impulse was hardly palpable. On percussion there was an increased area of cardiac dullness. The heart sound were distant but clear. A pleuropericardial friction rub was heard over the lower end of the sternum $\overrightarrow{0}$ There was dullness at the base of the right lung witho diminished breath sounds. Moist rales were heard over the left base. The liver was palpable three fingerbreadths below the costal margin and was tender. Paradoxical pulse, Broadbent's sign, ano systolic retractions at the apex were absent.

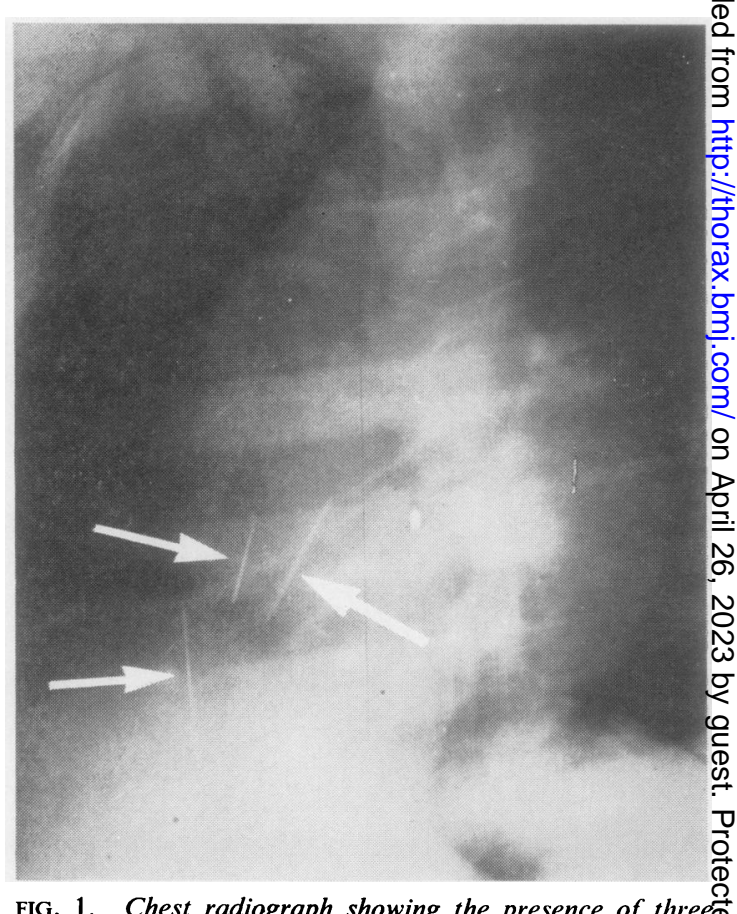

FIG. 1. Chest radiograph showing the presence of threec⿱艹 needles, two of which are seen to be embedded between the chest wall and the heart, while the third is thought to be embedded within the myocardium. 

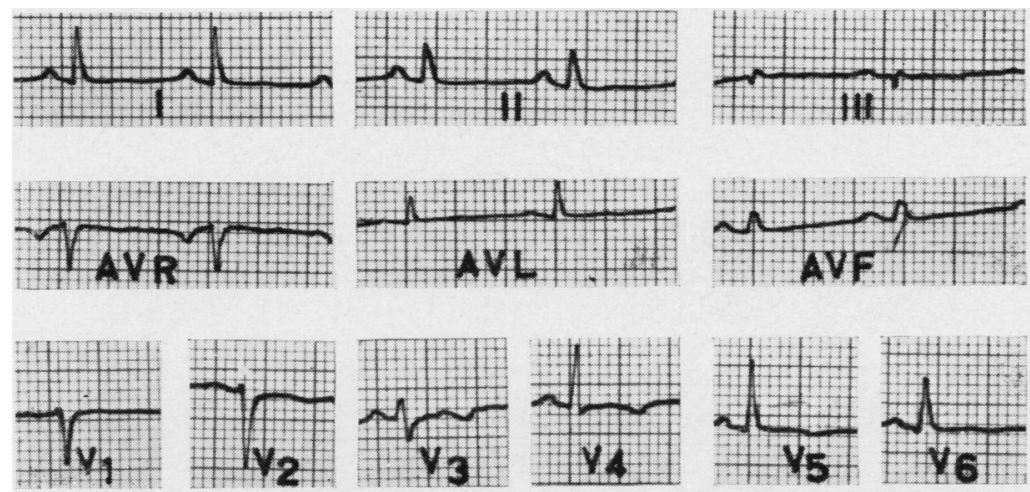

FIG. 2. Electrocardiogram one month after the insertion of three needles into the left hemithorax. Sinus rhythm, QRS equal $0.06 \mathrm{sec}$. The mean axis in the frontal plane is $+10^{\circ}$. There is low voltage of the $Q R S$ in all limb and precordial leads. $T$ waves are flattened in the limb leads. There is coving of the ST segment with T-inversion in leads $V_{3}$ to $V_{6}$.

The blood sedimentation rate was $40 \mathrm{~mm}$. in the first hour, the haemoglobin was $11.9 \mathrm{~g} . / 100 \mathrm{ml}$., and the white cell count was $7,400 / \mathrm{mm}^{3}$ Blood chemistry and urinalysis were normal. Radiographic examination of the chest (Fig. 1) revealed three needles in the left hemithorax. Two of the needles were seen to be embedded between the chest wall and the heart, while the third needle was thought to be embedded within the myocardium. On fluoroscopic examination this needle showed synchronous movements with the heart action. The electrocardiogram (Fig. 2) showed sinus rhythm with the mean frontal axis of the QRS complex $+10^{\circ}$. There was low voltage of the $Q R S$ complexes throughout and the $T$ wave was flattened in the limb leads. In addition, there was coving of ST segments with inverted $T$ waves in leads $V_{3}$ to $V_{6}$.

Towards the second half of November, oedema of both legs and swelling of the abdomen appeared. Physical examination at this time revealed a dyspnoeic and cyanotic patient. The neck veins were moderately distended. There was no definite change in the heart examination except for the heart sounds, which were very muffled. The pericardial friction rub seemed to be louder in the sitting position. The venous pressure, as measured in the antecubital vein, was $23 \mathrm{~cm}$. of saline, and the arm-to-tongue circulation time (calcium) was 10 seconds, while arm-tolung (ether) was 7 seconds.

The chest radiograph showed slight diminution of the heart shadow as compared with the previous picture, and kymography revealed a decrease in heart pulsations with 'plateau and V' pattern, which is said to be typical of constrictive pericarditis (Fig. 3). The electrocardiogram at that time showed deeper inversion of $T$ waves in $V_{2}$ to $V_{5}$ as compared with the previous electrocardiograms (Fig. 4). This suggested progression in the pattern of pericardial involvement.

Right heart catheterization revealed elevated pres- sures in both the superior and inferior venae cavae (mean values of 18 and $17 \mathrm{~mm}$. $\mathrm{Hg}$ respectively) and in the right atrium (mean $16.5 \mathrm{~mm}$. $\mathrm{Hg}$ ). The rightatrial-pressure curve showed an ' $M$ ' shape, while the right-ventricular-pressure curve showed an early diastolic dip.

Signs of congestive failure persisted in spite of bed rest and the administration of digitalis and diuretics. The fever subsided following antibiotic therapy. The patient was operated on four months after the insertion of the needles. A sternal-splitting incision was

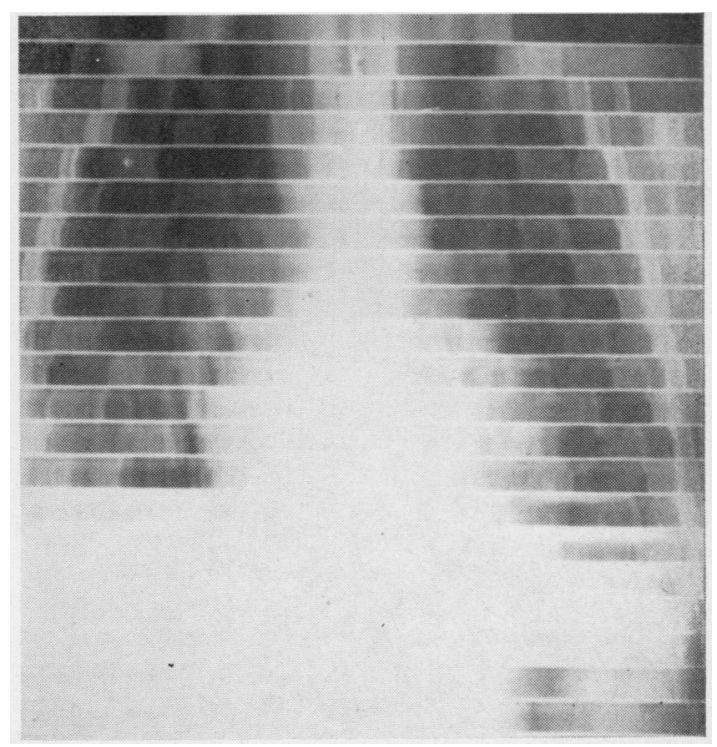

FIG. 3. Kymograph showing decrease in heart pulsations with 'plateau and $V$ ' pattern, which is said to be typical of constrictive pericarditis. 


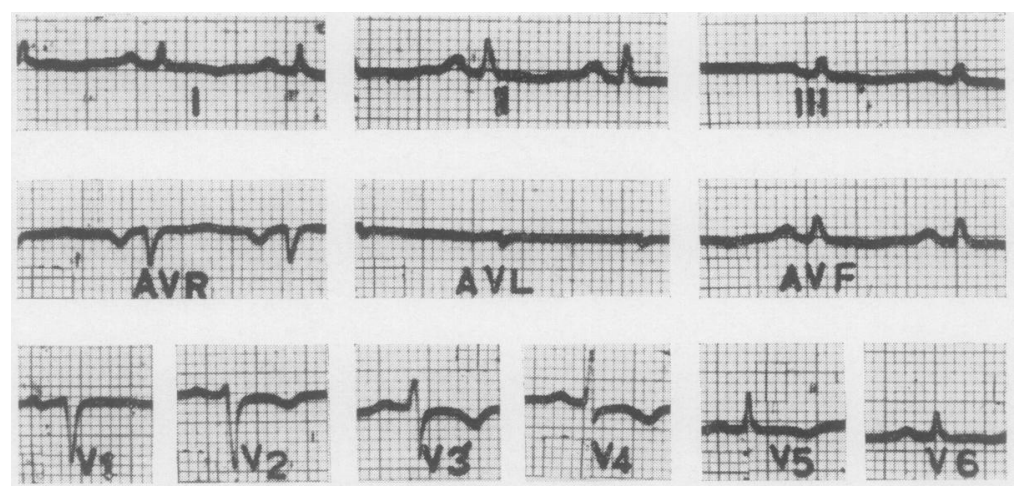

FIG. 4. Electrocardiogram five months after the insertion of the needles. There is inversion of the $T$ waves in leads I and II and deeper inversion of these waves in leads $V_{2}$ to $V_{5}$.

made and the pericardial sac was exposed. The amplitude of the cardiac pulsations was found to be diminished. The parietal pericardium was more than $10 \mathrm{~mm}$. thick. Complete removal of the anterior portion of the parietal pericardium revealed serosanguineous fluid which was evacuated. The needle itself was found buried in the diaphragmatic part of the myocardium, in the right ventricle, and was removed. Afiter dissection and removal of a thin fibrous sheath from the epicardium of the anterior cardiac wall, cardiac pulsations of normal amplitude began.

Histological study of the excised pericardium revealed chronic inflammatory changes with numerous plasma cells.

The patient was discharged 27 days after an uneventful post-operative course. All signs of congestive failure disappeared. Venous pressure dropped to $14 \mathrm{~cm}$. of saline, but the circulation time remained unchanged. One year later the patient again attempted suicide by inserting numerous needles into the left chest. Surgical intervention was again necessary because of abscess formation. No clinical signs of cardiac disorder were apparent.

\section{DISCUSSION}

The passage of pointed objects, e.g., pins and needles, into the heart wall is possible through four main routes: (1) the insertion of the needle directly into a blood vessel and subsequent migration, by the blood stream, to the heart. Such an occurrence was reported by Shapiro (1941) and by Barrett (1950), with the needle coming to lie, in Shapiro's case, in the pericardial fat between the heart and the diaphragm ; (2) the insertion of the object into soft tissues distant from the heart and subsequent slow migration through the tissues to the heart; (3) direct introduction of a pointed object through the chest wall into the heart ; (4) by penetration of a needle, impacted in the lower end of the oesophagus, into the righ ventricle. Goldberger and Clark (1935) described an unusual case in which a needle accidentally $\overrightarrow{0}$ penetrated the chest wall of a man during sleep. I

Reports dealing with the problem of foreigio bodies in the heart wall usually emphasize thag not all cases should be operated on immediately but should be kept under close observation (Singleton, 1933 ; Watts and Toone, 1945). Ac응 cording to Kissane and Rose (1961), this state ment is valid for old wounds only, since in time many foreign bodies become encysted and will $\mathrm{d} \sigma^{\circ}$ no harm. However, removal of the foreign bod is desirable when it is found in the acute stage: after the injury. Gould (1960) found as an acci dental post-mortem finding two asymptomatio cases, one with a needle in the myocardium, the other in the pulmonary artery. In both instances the foreign body had been tolerated without clinis cal evidence of its presence and even withou pathological evidence of progressive injury Similar experience was reported by Shapir $\bar{\Theta}$ (1941), Friedberg (1949), White (1951), and Woof (1956).

The clinical picture of constrictive pericarditî was fully established in our case less than five months after the insertion of the needles. Infeco tion, undoubtedly, could account for the rapif development of the disease, as the patient devek oped fever during the first days following the suicidal attempt. In fact, infection is considere by several authors (Blalock and Burwell, 1941 Holman, 1949) to be a conditio sine qua non for the development of constrictive pericarditis, while the existence of small amounts of blood in tho pericardial sac is usually not considered to be responsible for the development of the fibrotie process. This is supported by the fact thag 
although haemorrhage into the pericardial sac is common after diagnostic needling of the heart, the subsequent development of constrictive pericarditis is most unusual, as the blood is resorbed before any fibrosis develops (Greene, Sharp, Griffith, Bunnell, and Macmanus, 1958 ; Fleming, Hancock, Milstein, and Ross, 1958 ; Schaffer, 1961). In our patient a relatively short period of only five months was required for the constriction to become fully established. This contrasts with an average period of three years when tuberculosis is the aetiological factor (Deterling and Humphreys, 1955 ; Robertson and Arnold, 1962), and with a period of six years in the case reported by Straus (1944), where the pericarditis was caused by a needle in the heart wall. Constriction developed less than three months after the onset of a typical acute, non-specific pericarditis in a case reported by Rabiner, Specter, Ripstein, and Schlecker (1954). Deterling and Humphreys (1955) considered three factors to be important in the development of constrictive pericarditis: (1) prolonged exposure of the pericardium to irritants or damaging agents (tuberculosis, foreign body, clot, etc.); (2) an extending pericardial involvement rather than a discrete localized one; and (3) a varying degree of compression and constriction. Only the first factor seems applicable to our case, although the period of exposure was only five months.

As soon as significant signs of constriction appear, surgical intervention is indicated in order to prevent further myocardial damage (Watts and Toone, 1945 ; Rabiner et al., 1954 ; Deterling and Humphreys, 1955; Lancet, 1957 ; Darke and Chesterman, 1959). In one of the reported cases (Rabiner et al., 1954) operation was performed as early as three months after the onset of acute benign pericarditis. The benefit gained by the patient may be immediate, and further improvement should be anticipated within a few months. The drop in venous pressure in our patient (from 23 to $14 \mathrm{~cm}$. of saline) served as a good indicator in the evaluation of the operative success.
We wish to thank Professor Ch. Sheba, Head of the Department of Medicine, for permission to publish the case report.

\section{REFERENCES}

Barrett, N. R. (1950). Foreign bodies in the cardiovascular system. Brit.J. Surg., 37, 416.

Blalock, A., and Burwell, C. S. (1941). Chronic pericardial disease: report of 28 cases of constrictive pericarditis. Surg. Gynec. Obstet., 73, 433.

Darke, C. S., and Chesterman, J. T. (1959). Chronic localized constrictive pericarditis. Brit. J. Surg., 46, 615.

Deterling, R. A., and Humphreys, G. H. (1955). Factors in the etiology of constrictive pericarditis. Circulation, 12, 30.

Fleming, H. A., Hancock, E. W., Milstein, B. B., and Ross, D. N. (1958). Percutaneous left ventricular puncture with catheterization of the aorta. Thorax, 13, 97.

Friedberg, C. K. (1949). Diseases of the Heart, p. 980. Saunders, Philadelphia.

Glenn, E. E. (1940). Traumatic constrictive pericarditis. J. Miss. med. Ass., 37, 7.

Goldberger, H. A., and Clark, H. E. (1935). Migration of needle into heart through chest wall: surgical removal. Electrocardiographic and roentgenographic studies. J. Amer. med. Ass., 105, 193.

Gould, S. E. (1960). Pathology of the Heart, 2nd ed., p. 848. Thomas, Springfield, Illinois.

Greene, D. G., Sharp, J. T., Griffith, G. T., Bunnell, I. L., and Macmanus, J. E. (1958). Surgical applications of anterior percutaneous left heart puncture. Surgery, 43, 1.

Holman, E. (1949). The recognition and correction of constrictive pericarditis. J. thorac. Surg., 18, 643.

Kissane, R. W., and Rose, S. M. (1961). Traumatic pericarditis. Amer. J. Cardiol., 7, 97.

Lancet (1957). Annotations, 1, 204.

McKusick, V. A. (1952). Chronic constrictive pericarditis. Bull. Johns Hopk. Hosp., $90,3$.

Mortensen, V., and Warburg, E. (1948). Chronic constrictive pericarditis. Acta med. scand., 131, 203.

Rabiner, S. F., Specter, L. S., Ripstein, C. B., and Schlecker, A. A. (1954). Chronic constrictive pericarditis as a sequel to acute benign pericarditis. New Engl. J. Med., 251, 425.

Robertson, R., and Arnold, C. R. (1962). Constrictive pericarditis with particular reference to etiology. Circulation, 26, 525 .

Schaffer, A. I. (1961). A case of traumatic pericarditis with chronic tamponade and constriction. Amer. J. Cardiol., 7, 125.

Shapiro, S. (1941). Passage of a hollow needle into the venous blood stream to the heart, through the cardiac wall, and into the thorax. Report of a case. Amer. Heart J., 22, 835.

Singleton, A. O. (1933). Wounds of the heart. Amer. J. Surg., $20,515$.

Straus, B. (1944). Chronic constrictive pericarditis due to a foreign body (needle) in the pericardium. Amer. Heart J., 28, 805.

Warburg, E. (1933). Traumatisk Hjertesygdom. Panserhjerte-Pick's sygdrom. Nord. med. T., 6, 833 .

Watts, T. D., and Toone, E. L. (1945). Successful removal of foreign bodies within the pericardium. A report of two cases. Surgery, 18,685 .

White, P. D. (1951). Heart Disease, 4th ed., p. 606. Macmillan, New York.

Wood, P. (1956). Diseases of the Heart and Circulation, 2nd ed., p. 677. Eyre and Spottiswoode, London. 